\title{
Factors Affecting Smoking Initiation and Cessation Among Saudi Women Attending Smoking Cessation Clinics
}

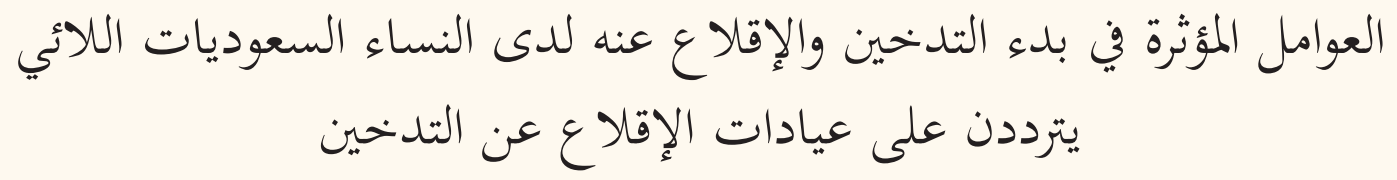

يُمن آل نمر، غادة فرحات، علي الوادعي

ABSTRAC T: Objectives: Smoking is one of the most adaptable risk behaviours associated with increased mortality rates, yet over one billion individuals worldwide are smokers. This study aimed to examine self-reported reasons for starting and quitting smoking among women attending smoking cessation clinics in Saudi Arabia. Methods: This cross-sectional study took place between January 2014 and January 2017 in Saudi Arabia using previously collected data. A survey was distributed to 3,000 female smokers attending smoking cessation programmes in 18 clinics from different regions in Saudi Arabia to determine self-reported reasons for smoking initiation and willingness/ unwillingness to quit. Results: A total of 2,190 women participated in the study (response rate $=73 \%$ ). Overall, the most common reason for starting to smoke was friends (31.1\%), while the predominant reason for willingness to quit was health concerns (45.5\%). The most frequent reason for being unwilling to quit smoking was a fear of mood changes (28\%). Conclusion: Most Saudi women are socially-driven to start smoking, while the most common reason for quitting is health concerns. The latter finding is promising in that it shows that smokers are gaining awareness of the adverse effects of smoking.

Keywords: Tobacco Smoking; Smoking Cessation; Health Risk Behaviors; Lifestyle Risk Reduction; Primary Health Care; Saudi Arabia.

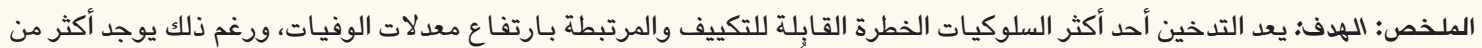

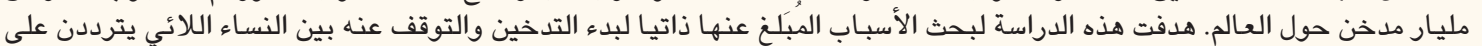

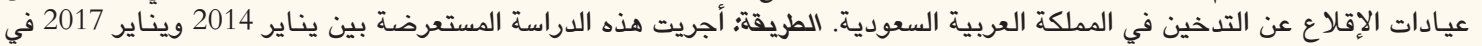

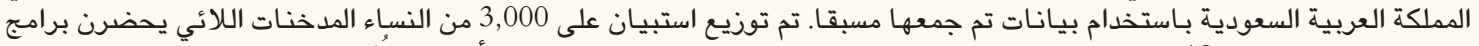

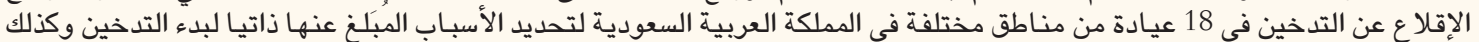

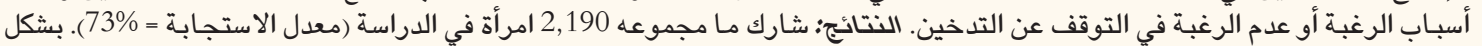

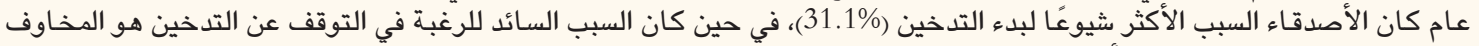

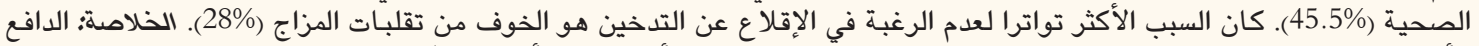

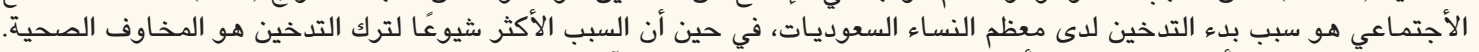
وتعتبر هذه النتيجة الأخيرة واعدة حيث أنها تكشف الأتساب المدخنين للوعي بآثار التدخين التهين السلبية.

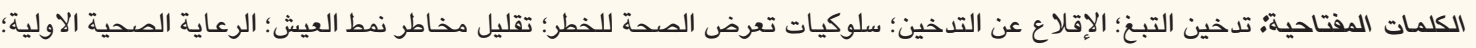
المملكة العربية السعودية.

$\mathrm{T}$ OBACCO SMOKING IS A MAJOR PUblic HEALTH problem worldwide, leading to various health problems including lung cancer, respiratory disorders (i.e. chronic obstructive pulmonary disease), eye-related diseases and arthritis. ${ }^{1,2}$ Moreover, smoking not only harms smokers, but also those around them with second-hand smoke exposure responsible for over 600,000 deaths annually. ${ }^{3}$

For women, smoking during pregnancy may lead to antenatal and postpartum complications, as well as an increased risk of infants of low birth weight and who are small-for-gestational age (SGA). ${ }^{4-6}$ Cigarettes are composed of various substances, such as nicotine and tar, which can cause pregnancy-related diabetes, hypertension and intrauterine growth restriction, conditions significantly associated with SGA infants. ${ }^{5,6}$ For many pregnant women, such adverse health effects contribute to reasons for smoking cessation once they realise that they are pregnant.,

As part of the National Smoking Cessation Programme (NSCP), clinics offering free standardised smoking cessation support have been established in 
various regions of Saudi Arabia, with a wide range of services available including cognitive behavioural therapy, nicotine replacement therapy (NRT) and nonNRT treatment, among others. ${ }^{9}$ Nevertheless, there is a shortage of information concerning the characteristics of female Saudi smokers, particularly with regards to factors that would aid smoking cessation efforts. As such, this study aimed to describe the characteristics of female Saudi smokers and their self-reported reasons for starting to smoke and willingness/unwillingness to quit smoking.

\section{Methods}

This cross-sectional study took place between January 2014 and January 2017. Previously collected data from 18 clinics offering smoking cessation programmes which are located in various regions of Saudi Arabia were analysed. A total of 3,000 Saudi females attending these clinics for the first time were invited to participate in the study. Self-administered English, with Arabic translation, questionnaires were used to gather data from the participants, including sociodemographic characteristics (i.e. age, education level and monthly income), the participant's weight and height, previous attempts to quit smoking and the presence of any other smokers at home, as well as self-reported reasons for smoking initiation and willingness/unwillingness to quit smoking.

The latter part of the survey consisted of 18 questions, including six potential reasons for smoking initiation (i.e. friends who smoke, family members who smoke, social imitation, stress, advertising and other), six reasons for being willing to quit smoking (i.e. health, to save money, religious beliefs, familial pressure, wanting to live a better life and other) and six reasons for being unwilling to quit smoking (i.e. cost of treatment, fear of mood changes, peer pressure, fear of failure, previous failure when attempting to quit and other). Participants were required to choose responses on a five-point Likert scale ranging from 'strongly disagree' to 'strongly agree' for each question.

Body mass index (BMI) was calculated from selfreported weight and height, with participants categorised as underweight, normal weight or overweight. Data concerning the participants' age, BMI category, location of clinic, education level, monthly income, presence of another smoker at home and previous attempts to quit smoking were presented in percentages and frequencies. In terms of reasons for smoking initiation, cessation and unwillingness to quit, results were presented as the frequency and percentage of respondents answering 'strongly agree', along with 95\% confidence intervals (CIs) due to a large proportion of missing data for each variable.

Approval to use the data presented in this study was obtained from the supervisor general of the NSCP in Riyadh, Saudi Arabia. All participants gave written informed consent prior to their participation in the study. The women were informed that all participation was voluntary and that they could withdraw from the study at any time. In addition, they were reassured that their contributions were anonymous and confidential.

\section{Results}

Overall, 2,190 women took part in the study (response rate $=73 \%$ ). Of these, $40.9 \%$ were $\leq 30$ years old and $50.5 \%$ attended clinics in either Jeddah or Makkah $(24.4 \%$ and $26.1 \%$, respectively). Only $12 \%$ were overweight. In terms of education level, 21\% had a Bachelor's degree and $19.6 \%$ had a high school diploma. Over a quarter (26.3\%) reported having no income. Most women (67.4\%) reported the presence of another smoker at home [Table 1].

The most common reason for starting to smoke was friends who smoke (31.1\%, 95\% CI: 29.2-33.1), followed by family members who smoke (8.3\%, 95\% CI: 7.2-9.5). Overall, $42.3 \%$ (95\% CI: 40.3-44.4) of the participants reported being influenced by social factors. This finding emerged after aggregating responses to three reasons (having a family member who smokes, having a friend who smokes, and social imitation). However, there were missing data for $55.5 \%$ of the participants regarding evidence that they were influenced to smoke by their friends; there were also missing data for other variables [Table 2].

In terms of willingness to quit smoking, the most common reason cited was health concerns (45.5\%, 95\% CI: 43.4-47.6), followed by familial pressure (20.4\%, 95\% CI: 18.7-22.1) and religious beliefs (18.1\%, 95\% CI: 16.5-19.8). Finally, 14.7\% (95\% CI: 13.3-16.3) and $14.3 \%$ (95\% CI: $12.9-15.9$ ) of the participants reported that their willingness to quit was in order to save money and have a better life, respectively. There were missing data for $54.3 \%$ of participants who were willing to quit smoking due to health concerns; in addition, there were missing data for other variables [Table 3].

Some of the women indicated that they were unwilling to quit smoking. Reasons for this included a fear of mood changes (28\%, 95\% CI: 26.1-29.9), peer pressure (18.5\%, 95\% CI: 16.9-20.2), cost of treatment (13.2\%, 95\% CI: 11.9-14.7), fear of failure (11.2\%, 95\% CI: 9.9-12.6) and failure after previous attempt(s) to quit (7.8\%, 95\% CI: 6.7-9). However, data were missing 
Table 1: Demographic characteristics of women attending smoking cessation clinics in Saudi Arabia $(\mathrm{N}=2,190)$

\begin{tabular}{|c|c|}
\hline Characteristic & n (\%) \\
\hline \multicolumn{2}{|l|}{ Age in years } \\
\hline $10-15$ & $181(8.3)$ \\
\hline $16-20$ & $110(5)$ \\
\hline $21-25$ & $283(12.9)$ \\
\hline $26-30$ & $322(14.7)$ \\
\hline $31-35$ & $267(12.2)$ \\
\hline $36-40$ & $76(3.5)$ \\
\hline $41-45$ & $149(6.8)$ \\
\hline $46-50$ & $53(2.4)$ \\
\hline $51-55$ & $142(6.5)$ \\
\hline $56-60$ & $184(8.4)$ \\
\hline$>60$ & $423(19.3)$ \\
\hline \multicolumn{2}{|l|}{ Location of clinic } \\
\hline Al-Madinah & $69(3.2)$ \\
\hline Eastern region & $44(2)$ \\
\hline Jeddah & $535(24.4)$ \\
\hline Jizan & $45(2.1)$ \\
\hline Makkah & $572(26.1)$ \\
\hline Northern borders & $153(7)$ \\
\hline Riyadh & $37(1.7)$ \\
\hline Central region & $461(21.1)$ \\
\hline Taif & $228(10.4)$ \\
\hline Other* & $46(2.1)$ \\
\hline \multicolumn{2}{|l|}{ Education level } \\
\hline Illiterate & $58(2.6)$ \\
\hline Primary school & $83(3.8)$ \\
\hline Middle school & $142(6.5)$ \\
\hline High school & $429(19.6)$ \\
\hline Diploma & $120(5.5)$ \\
\hline Bachelor's degree & $459(21)$ \\
\hline Master's degree & $18(0.8)$ \\
\hline Doctorate & $6(0.3)$ \\
\hline Other & $168(7.7)$ \\
\hline Unknown & $707(32.3)$ \\
\hline \multicolumn{2}{|c|}{ Monthly income in Saudi Riyals } \\
\hline None & $577(26.3)$ \\
\hline$<3,000$ & $206(9.4)$ \\
\hline $3,000-5,999$ & $264(12.1)$ \\
\hline $6,000-10,000$ & $174(7.9)$ \\
\hline$>10,000$ & $93(4.2)$ \\
\hline Unknown & $876(40)$ \\
\hline \multicolumn{2}{|c|}{ Presence of other smokers at home } \\
\hline Yes & $1,475(67.4)$ \\
\hline No & $715(32.6)$ \\
\hline \multicolumn{2}{|c|}{ Body mass index category } \\
\hline Underweight & $350(16)$ \\
\hline Normal weight & $733(33.5)$ \\
\hline Overweight & $262(12)$ \\
\hline Unknown & $845(38.6)$ \\
\hline \multicolumn{2}{|c|}{ Previous attempts at quitting } \\
\hline Yes & $575(26.3)$ \\
\hline No & $1,615(73.7)$ \\
\hline
\end{tabular}

"Including nine clinics with $\leq 20$ participants each located in Al-Bahah, Al-Jawf, Al-Qassim, Qurrayat, Aseer, Bisha, Hafar Al-Batin, Najran and Tabuk.
Table 2: Reasons for smoking initiation among women attending smoking cessation clinics in Saudi Arabia $(\mathrm{N}=2,190)$

\begin{tabular}{lccc} 
Reason* $^{*}$ & \multicolumn{2}{c}{$\mathbf{n}(\%)$} & 95\% CI \\
& $\begin{array}{c}\text { Strongly } \\
\text { agree }\end{array}$ & $\begin{array}{c}\text { Missing } \\
\text { data }\end{array}$ & \\
Friends who smoke & $682(31.1)$ & $1,216(55.5)$ & $29.2-33.1$ \\
$\begin{array}{l}\text { Family members } \\
\text { who smoke }\end{array}$ & $181(8.3)$ & $1,705(77.9)$ & $7.2-9.5$ \\
Stress & $125(5.7)$ & $1,840(84)$ & $4.8-6.8$ \\
Social imitation & $64(2.9)$ & $1,815(82.9)$ & $2.7-3.7$ \\
Advertising & $22(1)$ & $2,002(91.4)$ & $0.6-1.5$ \\
Other & $71(3.2)$ & $2,093(95.6)$ & $2.5-4.1$
\end{tabular}

$C I=$ confidence interval. "Percentages do not add up to $100 \%$ as the rem aining participants chose responses ranging from 'agree' to 'strongly disagree'.

Table 3: Reasons for willingness to quit smoking among women attending smoking cessation clinics in Saudi Arabia $(\mathrm{N}=2,190)$

\begin{tabular}{lccc} 
Reason* & \multicolumn{2}{c}{ n (\%) } & 95\% CI \\
& $\begin{array}{c}\text { Strongly } \\
\text { agree }\end{array}$ & $\begin{array}{c}\text { Missing } \\
\text { data }\end{array}$ & \\
Health concerns & $996(45.5)$ & $1,190(54.3)$ & $43.4-47.6$ \\
Familial pressure & $446(20.4)$ & $1,740(79.5)$ & $18.7-22.1$ \\
Religious beliefs & $397(18.1)$ & $1,789(81.7)$ & $16.5-19.8$ \\
To save money & $323(14.7)$ & $1,863(85.1)$ & $13.3-16.3$ \\
To have a better life & $314(14.3)$ & $1,872(85.5)$ & $12.9-15.9$ \\
Other & $30(1.4)$ & $2,156(98.4)$ & $0.9-2$
\end{tabular}

$C I=$ confidence interval. "Percentages do not add up to $100 \%$ as the remaining participants chose responses ranging from 'agree' to 'strongly disagree'.

Table 4: Reasons for unwillingness to quit smoking among women attending smoking cessation clinics in Saudi Arabia $(\mathrm{N}=2,190)$

\begin{tabular}{|c|c|c|c|}
\hline \multirow[t]{2}{*}{ Reason* } & \multicolumn{2}{|c|}{ n (\%) } & \multirow[t]{2}{*}{$95 \% \mathrm{CI}$} \\
\hline & $\begin{array}{l}\text { Strongly } \\
\text { agree }\end{array}$ & $\begin{array}{l}\text { Missing } \\
\text { data }\end{array}$ & \\
\hline $\begin{array}{l}\text { Fear of mood } \\
\text { changes }\end{array}$ & $613(28)$ & $1,900(86.8)$ & $26.1-29.9$ \\
\hline Peer pressure & 405 (18.5) & $1,785(81.5)$ & $16.9-20.2$ \\
\hline Cost of treatment & $290(13.2)$ & $1,900(86.8)$ & $11.9-14.7$ \\
\hline Fear of failure & $245(11.2)$ & $1,945(88.8)$ & $9.9-12.6$ \\
\hline $\begin{array}{l}\text { Failed previous } \\
\text { attempt(s) }\end{array}$ & $170(7.8)$ & $2,020(92.2)$ & $6.7-9$ \\
\hline Other & $65(3)$ & $2,125(97)$ & $2.3-3.8$ \\
\hline
\end{tabular}

$C I=$ confidence interval. "Percentages do not add up to $100 \%$ as the remaining participants chose responses ranging from 'agree' to 'strongly disagree'.

for $86.8 \%$ of participants concerning unwillingness to quit smoking due to fear of mood changes; there were missing data for other variables as well [Table 4].

\section{Discussion}

In the current study, the majority of Saudi women attending smoking cessation clinics were $\leq 40$ years old. Other studies have noted that most women start 
smoking in their early 20 s. ${ }^{10-12}$ This often occurs while attending college or university, perhaps as a result of being surrounded by peers who believe that smoking is fashionable. ${ }^{13-16}$ Importantly, the present study noted that peer pressure, especially from friends, was the main reason that women started smoking.

Research indicates that most young adult smokers lack critical information regarding the adverse health effects of tobacco smoking. ${ }^{17}$ Nevertheless, even with knowledge of the associated risks, friendship plays a crucial role in smoking behaviours among young adult females. ${ }^{14}$ A study involving young women attending a college in Dammam, Saudi Arabia, similarly observed that their introduction to smoking was due to seeing this behaviour reflected in someone they knew. ${ }^{18}$ As such, it is imperative that anti-smoking strategies be integrated into higher educational institutions in Saudi Arabia in order to reach a greater number of young adults.

The majority of women in the current study expressed a willingness to quit smoking, with the most common reason being health concerns. This is encouraging as it indicates that most Saudi women attending smoking cessation programmes are aware of the adverse effects of tobacco smoking on their health. The Ministry of Health in Saudi Arabia has already initiated efforts to incorporate health messages on cigarette packaging to ensure consumers are aware of the consequences of smoking. ${ }^{19,20}$ However, while health was reported to be the most important reason to quit smoking among Saudi women in the present study, it was not possible to discern which precise health concern most encouraged these women to consider quitting.

Smoking cessation programmes are among the most cost-effective and successful strategies for helping people to quit smoking. ${ }^{20}$ In Saudi Arabia, comprehensive tobacco control measures, including bans on smoking in public places and high taxation on tobacco products, have also contributed to high cessation rates in the general population. ${ }^{9}$ Based on the findings of the present study, smoking dependence clinics should be established on the campuses of Saudi Arabian colleges and tobacco smoking cessation programmes integrated into the curricula. In addition, the authors recommend that the NSCP integrate referral to cessation clinics into routine clinical care.

The strengths of this study include the large sample size which was nationally representative, covering all regions of Saudi Arabia, and the use of a uniform data collection method via a standardised questionnaire. However, there were a number of limitations. There were many missing values which were not categorised, making it difficult to discern between 'true' missing values and inapplicable answers; indeed, in terms of reasons for smoking initiation and cessation, some answer choices had missing values for more than 90\% of the sample. As such, certain variables could not be properly analysed and the results should be taken in light of this limitation.

Another limitation was the exclusion of other important reasons for willingness to stop smoking such as pregnancy. While this reason might have been subsumed under the health concerns category, it would have been interesting to study the influence of this variable independently. In addition, the findings may have been affected by recall bias, particularly with regards to reasons for smoking initiation if the participant had been smoking for a number of years. Other variables, such as age, should have been collected on a continuous scale; however, as age was not stratified beyond this level of detail in the original questionnaire, it was not possible to determine if there were younger respondents.

\section{Conclusion}

Social factors are the primary reasons for smoking initiation among the studied sample of women in Saudi Arabia while health concerns were the main reason for smoking cessation, followed by familial pressure, religion, saving money and having a better life. Additional on-campus smoking cessation clinics should be introduced at colleges in Saudi Arabia in order to target younger smokers. Furthermore, the authors recommend that referral to cessation clinics be integrated into routine clinical care.

\section{CONFLICT OF INTEREST}

The authors declare no conflicts of interest.

\section{FUNDING}

No funding was received for this study.

\section{References}

1. Bonnie RJ, Stratton K, Kwan LY, Eds. The effects of tobacco use on health. In: Public Health Implications of Raising the Minimum Age of Legal Access to Tobacco Products. Washington DC, USA: National Academies Press, 2015. https://doi.org/10.17226/18997.

2. El-Zaatari ZM, Chami HA, Zaatari GS. Health effects associated with waterpipe smoking. Tob Control 2015; 24:i31-43. https://doi.org/10.1136/tobaccocontrol-2014-051908.

3. Oberg M, Jaakkola MS, Woodward A, Peruga A, Prüss-Ustün A. Worldwide burden of disease from exposure to secondhand smoke: A retrospective analysis of data from 192 countries. Lancet 2011; 377:139-46. https://doi.org/10.1016/S01406736(10)61388-8. 
4. Chiolero A, Bovet P, Paccaud F. Association between maternal smoking and low birth weight in Switzerland: The EDEN study. Swiss Med Wkly 2005; 135:525-30. https://doi.org/2005/35/ smw-11122.

5. Ko TJ, Tsai LY, Chu LC, Yeh SJ, Leung C, Chen CY, et al. Parental smoking during pregnancy and its association with low birth weight, small for gestational age, and preterm birth offspring: A birth cohort study. Pediatr Neonatol 2014; 55:20-7. https://doi.org/10.1016/j.pedneo.2013.05.005.

6. Reeves S, Bernstein I. Effects of maternal tobacco-smoke exposure on fetal growth and neonatal size. Expert Rev Obstet Gynecol 2008; 3:719-30. https://doi.org/10.1586/1747 4108.3.6.719.

7. Kataoka MC, Carvalheira AP, Ferrari AP, Malta MB, de Barros Leite Carvalhaes MA, de Lima Parada CM. Smoking during pregnancy and harm reduction in birth weight: A crosssectional study. BMC Pregnancy Childbirth 2018; 18:67. https://doi.org/10.1186/s12884-018-1694-4.

8. Levis DM, Stone-Wiggins B, O’Hegarty M, Tong VT, Polen KN, Cassell $\mathrm{CH}$, et al. Women's perspectives on smoking and pregnancy and graphic warning labels. Am J Health Behav 2014; 38:755-64. https://doi.org/10.5993/AJHB.38.5.13.

9. Moradi-Lakeh M, El Bcheraoui C, Tuffaha M, Daoud F, Al Saeedi M, Basulaiman $\mathrm{M}$, et al. Tobacco consumption in the Kingdom of Saudi Arabia, 2013: Findings from a national survey. BMC Public Health 2015; 15:611. https://doi.org/10.1186/s12889015-1902-3

10. Al-Mohrej OA, Al-Shirian SD, Altraif SI, Tamim HM, Fakhoury HMA. What encourages Saudis to quit smoking? J Health Spec 2016; 4:146-50. https://doi.org/10.4103/1658-600X.179825.

11. Koura MR, Al-Dossary AF, Bahnassy AA. Smoking pattern among female college students in Dammam, Saudi Arabia. Family Community Med 2011; 18:63-8. https://doi.org/10.410 3/2230-8229.83370.

12. Chezhian C, Murthy S, Prasad S, Kasav JB, Mohan SK, Sharma S, et al. Exploring factors that influence smoking initiation and cessation among current smokers. J Clin Diagn Res 2015; 9:LC08-12. https://doi.org/10.7860/JCDR/2015/12047.5917.
13. Anjum MS, Srikanth MK, Reddy PP, Monica M, Rao KY, Sheetal A. Reasons for smoking among the teenagers of age 14-17 years in Vikarabad town: A cross-sectional study. J Indian Assoc Public Health Dent 2016; 14:80-3. https://doi. org/10.4103/2319-5932.178733.

14. Wray RJ, Jupka K, Berman S, Zellin S, Vijaykumar S. Young adults' perceptions about established and emerging tobacco products: Results from eight focus groups. Nicotine Tob Res 2012; 14:184-90. https://doi.org/10.1093/ntr/ntr168.

15. Pepper JK, Reiter PL, McRee AL, Cameron LD, Gilkey MB, Brewer NT. Adolescent males' awareness of and willingness to try electronic cigarettes. J Adolesc Health 2013; 52:144-50. https://doi.org/10.1016/j.jadohealth.2012.09.014.

16. Saari AJ, Kentala J, Mattila KJ. The smoking habit of a close friend or family member--How deep is the impact? A crosssectional study. BMJ Open 2014; 4:e003218. https://doi.org/10.1 136/bmjopen-2013-003218.

17. Glenn NM, Lapalme J, McCready G, Frohlich KL. Young adults' experiences of neighbourhood smoking-related norms and practices: A qualitative study exploring place-based social inequalities in smoking. Soc Sci Med 2017; 189:17-24. https://doi.org/10.1016/j.socscimed.2017.07.021.

18. Ansari K, Farooqi FA. Comparison and prevalence of smoking among Saudi females from different departments of the College of Applied Medical Sciences in Dammam. Int J Health Sci (Qassim) 2017; 11:56-62.

19. Hiilamo H, Crosbie E, Glantz SA. The evolution of health warning labels on cigarette packs: The role of precedents, and tobacco industry strategies to block diffusion. Tob Control 2014; 23:e2. https://doi.org/10.1136/tobaccocontrol-2012-050541.

20. World Health Organization. (2017). WHO report on the global tobacco epidemic, 2017: Monitoring tobacco use and prevention policies. From: https://who.int/tobacco/global_ report/2017/en/ Accessed: Jun 2019. 